\title{
Time through colors: A kinetic model of red vermilion darkening from Raman spectra
}

\author{
D. Chiriu ${ }^{\text {a, }}$, M. Pala ${ }^{\text {a }}$, F.A. Pisu ${ }^{\text {a }}$, G. Cappellini ${ }^{\text {a,b }}{ }^{\text {, P.C. Ricci }}{ }^{\text {a }}$, C.M. Carbonaro ${ }^{\text {a }}$

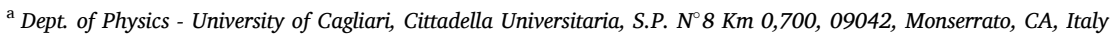 \\ ${ }^{\mathrm{b}}$ European Theoretical Spectroscopic Facility (ETSF), Italy
}

\section{A R T I C L E I N F O}

\section{Keywords:}

Vermilion darkening

Kinetic model

Pigment ageing

Cinnabar degradation

\begin{abstract}
A B S T R A C T
Darkening of Red Vermilion (cinnabar) is a well-known phenomenon which needs, at the moment, a full comprehension of its nature. Some paintings reveal a disfiguring process of blackening degradation of Red Vermilion, albeit other relics preserve the original color during the time. The presence of halide elements like $\mathrm{Cl}^{-}$ ions, in addition to the light exposure, represents the most alleged cause to explain the darkening phenomenon. However, the real effect of chlorine impurities is still not completely understood. In this study, starting from a multi-technique characterization, we propose a kinetic model of mutual composition of alpha/beta cinnabar derived by the experimental darkening of pure alpha synthetic cinnabar intentionally doped with $\mathrm{Cl}^{-}$ions and treated under prolonged UV light exposure. The model was further applied to ancient samples by analyzing the Raman spectra of antique cinnabar pigments belonging to manuscripts of XIII-XVII centuries.
\end{abstract}

\section{Introduction}

Color technology accompanies the human history since the Neolithic period [1-4]. Among the principal pigments used for decorating artifacts or paintings, mercury sulfide $\mathrm{HgS}$, known as cinnabar, assumed a prominent role as red color for many applications. In fact, cinnabar was used not only as pigment, but it found employment also as cosmetic, medicine and red ink. Several archeological sites report the use of cinnabar in ancient relics like Chinese potteries, Asian lacquer artifacts or mural paintings in Pompeii. Known also as Vermilion, it was very appreciated during the time, especially in the Middle Ages, Renaissance and Baroque, being found, among the others, in many paintings of Titian, Botticelli, Rembrandt and Rubens [2,5].

This pigment is considered generally stable, when it is pure and in absence of particular agents determining the so-called phenomenon of Vermilion darkening $[2,6,7]$. Indeed, there are specific impurities which may cause the effect of $\mathrm{HgS}$ degradation and, as evidenced in the literature, catalytic elements (halides for examples) accelerate the darkening process $[2,5,8]$. The mentioned degradation affected numerous artifacts during the time and involved not only paintings, but it is quite evident also in mural frescoes, obviously exposed to external agents (light, relative humidity and salt content in the atmosphere) $[1,2,5,6]$. Famous cases concern Egyptian and Pompeii frescoes as well as Renaissance mural paintings $[2,9]$. Considering the continuous studies on this phenomenon, as evidenced by recent works $[2,7,10]$, a deep understanding of the Vermillion darkening problem can contribute to evaluate the conservation state of many above mentioned artifacts and the efforts for their preservation.

\subsection{Structure of $\mathrm{HgS}$}

Several works report the crystal structure of the HgS system [11-13]. As reported by Ballirano et al. [1], the crystal structure of cinnabar can be identified in three different phases: red $\alpha$-HgS having trigonal structure ( $\mathrm{P} 3_{1} 21$ space group) with lattice constants $\mathrm{a}=4.1489 \AA$ And $\mathrm{c}$ $=9.4947 \AA$; black cubic $\beta$-HgS (F43 m space group) with lattice constant $\mathrm{a}=5.8461 \AA$; $\gamma$-HgS (hypercinnabar) with hexagonal structure and lattice constants $\mathrm{a}=7.0103 \AA$ and $\mathrm{c}=14.1307 \AA$. Due to the impurities in the composition, the $\alpha$-HgS phase converts to cubic metacinnabar $\beta$-HgS, in the temperature range between $373 \mathrm{~K}$ (HgS $99.97 \% \mathrm{wt})$ and $635 \mathrm{~K}$ (HgS $99.999 \% \mathrm{wt})[11,14]$. This transformation presents a value of enthalpy ranging from 2 to $8 \mathrm{~kJ} / \mathrm{mol}$. In addition, it was found a very low kinetic of the reverse transformation from $\beta$ - $\mathrm{HgS}$ to $\alpha-\mathrm{HgS}$ phase at room temperature [1]. At $798 \mathrm{~K}$ the metacinnabar transforms to hypercinnabar.

As enlightened above, many works indicated the purity of $\mathrm{HgS}$ as the

\footnotetext{
* Corresponding author.

E-mail address: daniele.chiriu@dsf.unica.it (D. Chiriu).
} 
discriminant element condition to prevent its darkening, thus several studies identified the production process of vermilion pigment, especially used in art, as the main cause of chemical contamination $[1,2,5-7$, $9,10]$.

\subsection{Production of $\mathrm{HgS}$ pigment}

The processes for obtaining vermilion involve two different techniques, sharing the characteristic that both methods imply the obtaining of vermilion via conversion reaction of black $\beta$-HgS. The dry method consists in the heating of mercury with sulphur in order to obtain the black phase $\beta$-HgS and thereafter the $\alpha$-HgS phase by a second heating step [9]. In this case the direct reaction leading to the formation of vermilion is complex and the temperature is the crucial parameter to exceed the kinetic barrier of the cubic to trigonal phase conversion. The second method provides vermilion by a wet process, much easier than the dry one. This method starts also from $\beta$ - $\mathrm{HgS}$ formed by the reaction of sulphur with mercury or mercury salts. The complete conversion of metacinnabar to vermilion requires strong basic media and moderate temperature $\left(\mathrm{NaOH} 4 \mathrm{M}-60{ }^{\circ} \mathrm{C}\right)[6,9]$.

\subsection{Darkening phenomenon}

Many references suggest different mechanisms ascribable to the darkening of cinnabar:

- Phase transformation from red hexagonal $\alpha$-cinnabar into black cubic $\beta$-cinnabar (called also metacinnabar): this case, formulated by Feller [15] and further studied in many other references, implies that reflectance properties of red cinnabar are altered by light exposure because of the production of dark phase metacinnabar [16-18]. The effect is accentuated by the original composition of the pigment in addition to its production process (wet or dry synthesis [9]).

- Formation of transition chloride compounds (mercury chlorides or sulfochlorides) which present a darker coloration with the consequent effect of total blackening of vermilion. These chlorine-based compound like calomel $\mathrm{Hg}_{2} \mathrm{Cl}_{2}$, terlinguaite $\mathrm{Hg}_{2} \mathrm{ClO}$, eglestonite $\mathrm{Hg}_{6} \mathrm{Cl}_{3} \mathrm{O}(\mathrm{OH})$, corderoite $\mathrm{Hg}_{3} \mathrm{~S}_{2} \mathrm{Cl}_{2}$ and kenhsuite $\mathrm{Hg}_{3} \mathrm{~S}_{2} \mathrm{Cl}_{2}$, are often instable and they dissociate re-forming, in particular cases of relative humidity $(\mathrm{RH})$ and $\mathrm{pH}$, amorphous mercury sulfide [2,5].

- Photochemical redox to obtain metallic $\mathrm{Hg}^{0}$ and $\mathrm{S}^{0}$, after catalysis by halogens at high RH under sunlight/UV exposure. The dark coloration is due to the presence of grey metallic $\mathrm{Hg}$ clusters into the red pigment $[7,19]$.

- Thermodynamic effect: dissociation of $\alpha-\mathrm{HgS}$ in metallic $\mathrm{Hg}^{0}$ and $\beta$-HgS, due to a transition temperature in the range $373-673 \mathrm{~K}$, as discussed before. The transition temperature can decrease drastically in presence of $\mathrm{Cl}$ ions, in the system $\mathrm{Hg}-\mathrm{S}-\mathrm{Cl}-\mathrm{H}_{2} \mathrm{O}$ with prevalence of $\mathrm{Hg}$ ions. As reported by Radepont et al. [6], at $300 \mathrm{~K}$ the effect of $\mathrm{pH}$ leads to a simultaneous presence of $\mathrm{Hg}^{0}$ and $\alpha-\mathrm{HgS}$ with mutual concentration depending on $\mathrm{pH}$. In this condition the presence of $\beta-\mathrm{HgS}$ is not excluded. However, a predominant concentration of $\mathrm{Cl}$ ions, depending on the $\mathrm{pH}$, implies the formation of Cl-based compounds like calomel or corderoite.

By considering the above-mentioned principal mechanisms of vermilion darkening, in this work we examined in depth the problem by exploiting a comparative analysis of synthetic and ancient samples. To explain the phenomenon, we propose a kinetic model of mutual composition of alpha/beta cinnabar derived by the experimental darkening of pure alpha synthetic cinnabar intentionally doped with $\mathrm{Cl}^{-}$ions and treated under prolonged UV light exposure. The analysis was carried out by means of a multi-technique approach including, among the others, Raman Spectroscopy. This technique gained, in the last decades, a key role in the study of chemical-physical process related to the cultural heritage [20-27]. Our approach is based on different fingerprints represented by Raman spectra of above-mentioned chlorine-based compounds like calomel or terlinguaite [18,28-31]. Indeed, as representatively shown in Fig. 1A (RRUFF database - ID R060492 and R070370), the chlorine compounds present intense bands at lower wavenumbers with respect to $\mathrm{HgS}$ phases (below $200 \mathrm{~cm}^{-1}$ ) [32]. In addition, the intensity ratios among the bands can be used to determine from one side the presence of specific compounds such as calomel or terlinguaite, from the other side to discriminate between $\beta$ - $\mathrm{HgS}$ and $\alpha$-HgS phases. This study, finally, is addressed to provide important elements for understanding the problem and formulate a preliminary model able to predict the degradation of the pigment as a function of the time and environment conditions.

\section{Materials and methods}

\subsection{Materials}

\subsubsection{Synthetic samples}

To study the darkening process of vermilion in painting and inks we realized synthetic samples doped with $\mathrm{Cl}^{-}$with the purpose to simulate the effect of this catalyst agent. Synthetic samples were prepared following a previous work of Neiman et al. which studied the role of $\mathrm{Cl}^{-}$ ions in relation to darkening phenomenon, and interpreted the results with the formation of transition chloride compounds [33].

Pure red cinnabar powders, provided by "Opificio Pietre Dure" (Florence - Italy), having $65 \mu \mathrm{m}$ grain and volume density of $8.1 \mathrm{~g} / \mathrm{cm}^{3}$ (Natural Cinnabar Monte Amiata 100\% - CAS-Nr: 1344-48-5 - Red/ Medium - Kremer Pigmente K10610- Pigment Red 106, C.I. 77766), were dispersed in distilled water and mixed with different molar concentration of $\mathrm{NaCl}$ in order to obtain a set of samples with variable $\mathrm{Cl}^{-}$ concentration. The volume ratio between pigment and solution was 1:25. All mixtures were hold under agitation for $1 \mathrm{~h}$ at room temperature.

Four different concentrations were selected with the intent to cover a wide range of $\mathrm{Cl}^{-}$ions. We report the assigned nomenclature of samples connected directly to the molar concentration: $0.00 \mathrm{M} \mathrm{NaCl}$ called "pure"; $0.01 \mathrm{M} \mathrm{NaCl}$ called "0.01 M", $0.1 \mathrm{M} \mathrm{NaCl}$ called "0.1 M" and $5 \mathrm{M}$ $\mathrm{NaCl}$ called " $5 \mathrm{M}$ ". Solutions were then applied to a specific support to obtain a pigment deposit available for our analysis. Depending on the analysis technique different supports were exploited as reported in the following:

- Raman, SEM/EDS and Pump-probe analysis: all solutions were dropped to glass slides and dried, with the final results of a solid deposit of about $100 \mu \mathrm{m}$ thickness and covering area of about $2 \mathrm{~cm}^{2}$.

- Reflectance measurements: Pure and $5 \mathrm{M}$ solutions were continuously dropped and dried upon an inert polyvinyl chloride (PVC) support, tool of our measurement apparatus, until we obtained a compacted homogenous powder deposit (disk with $\mathrm{r}=16 \mathrm{~mm}$, thickness $=1$ $\mathrm{mm})$.

All synthetic samples were treated under the UV light of a LED at 365 $\mathrm{nm}$ (emission with Lorentzian profile having full width half maximum of $10 \mathrm{~nm}$ ), under constant power density of $10 \mathrm{~mW} / \mathrm{cm}^{2}$, for time ranges between 0 and $200 \mathrm{~h}$.

Thermal treatments were performed keeping the glass slides with the samples in a controlled oven at $70{ }^{\circ} \mathrm{C}, 135^{\circ} \mathrm{C}$ and $200{ }^{\circ} \mathrm{C}$ for different time ranging from 0 to 10 days.

\subsubsection{Ancient manuscripts from "Biblioteca Universitaria di Cagliari"}

In order to extend the model proposed in this work to natural aging effects, we studied six ancient samples, belonging to the "Biblioteca Universitaria di Cagliari" BUCA, written in the range between 1435 and 1511 A.D. These samples were chosen because they were the oldest sample available and the most suitable to test our model. In addition, they present cinnabar inks of high purity, according to the preparative 

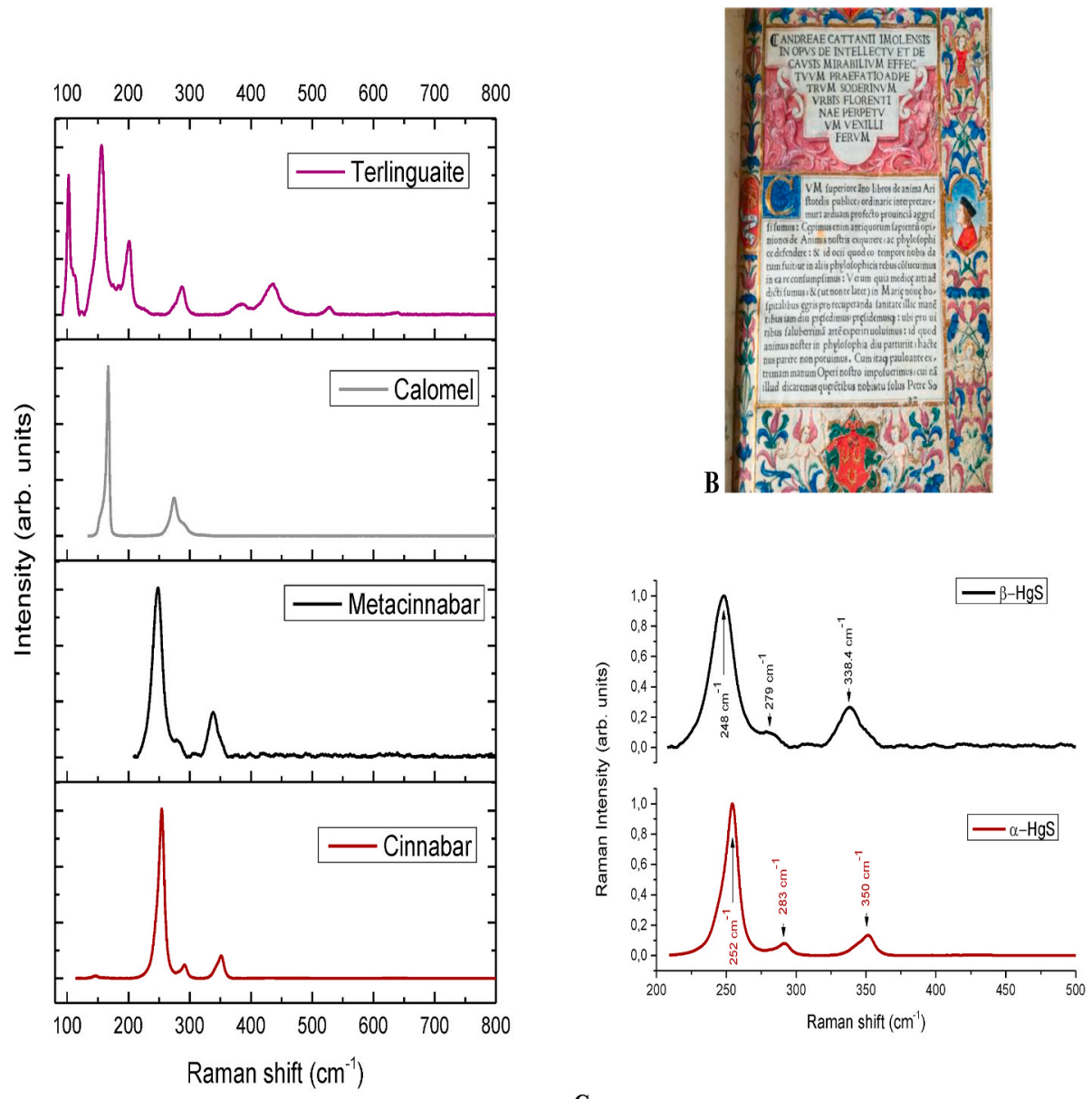

$\mathrm{C}$

Fig. 1. Reference Raman spectra used for comparative analyses. Raman spectra of cinnabar phases and chlorine-based compounds related to vermilion darekening (A). Picture of representative ancient sample from Biblioteca Universitaria di Cagliari (BUCA): Opus de intellectu et de causis mirabilium effectuum (before 1511) (B). Comparison between $\beta$-HgS and $\alpha$-HgS Raman spectra (C).

procedure of cinnabar in that age $[3,4,9]$. They represent important texts of the library used in the academia as theology, administrative and sciences references. The paper manuscripts are conserved at controlled atmosphere and were subjected to little restoration to preserve the cellulose support. Parchment manuscripts are conserved at controlled atmosphere and do not present restoration interventions. The complete list of the samples is reported in the following:

- Ruralium commodorum (1435, parchment support)

- Furs de Valencia (1482, paper support)

- Libri sententiarum (XV century, parchment support)

- De Sphaera mundi (1482, paper support)

- Kalendarium (1485, paper support)

- Opus de intellectu et de causis mirabilium effectuum (1511, paper support - see Fig. 1B)

All measurements on ancient samples were performed covering at least 5 points per "card" in which vermilion was applied as writing ink and color in illuminations (see example images reported in Supplementary Materials). Sampling consisted in acquiring the spectra at three different pages, namely at the first page, in the middle and at the end of the code, to achieve a total of 25 spectra per volume. Then, a single average spectrum was extracted as representative of the volume. Further details about codicology and sampling procedure can be found in Supplementary Materials (Fig. S1).

\subsection{Methods}

\subsubsection{Raman measurements}

High resolution micro Raman scattering measurements were obtained in back scattering geometry through the confocal system SOL Confotec MR750 equipped with Nikon Eclipse Ni microscope. Raman spectra were gathered by using, as excitation wavelength, the $785 \mathrm{~nm}$ line (IO MatchBox series laser diode). The system is equipped with four gratings $(150,600,1200$ and 1800 grooves $/ \mathrm{mm})$ which can be selected depending on the measure requirements. The grating with 1800 grooves $/ \mathrm{mm}$ was used to obtain a resolution of $0.2 \mathrm{~cm}^{-1}$.

In situ micro Raman scattering measurements were carried out in back scattering geometry with the $1064 \mathrm{~nm}$ line of an Nd:YAG laser. Measurements were performed in air at room temperature with a compact spectrometer B\&WTEK (Newark-USA) i-Raman Ex integrated system with a spectral resolution of $8 \mathrm{~cm}^{-1}$. For each experimental setup, all the spectra were collected with an acquisition time of about 60 $\mathrm{s}$ (five replicas) and power excitation between 5 and $10 \mathrm{~mW}$ concentrated in a spot of $0.3 \mathrm{~mm}^{2}$ on the surface through a Raman Video MicroSampling System (Nikon Eclipse for high-resolution and BAC151B in the other case) equipped with a $20 \times$ Olympus objective to select the area on the samples. These conditions were selected after preliminary studies as safe conditions for the samples in order to avoid the effect reported in Ref. [34]. Each measurement area represents a sampling surface of about $1 \mathrm{~cm}^{2}$. 


\subsubsection{SEM/EDS measurements}

SEM images were gathered by a scanning electron microscope ESEM: FEI Quanta 200 under low vacuum conditions. EDS semiquantitative analyses were obtained with the help of Thermo Scientific EDS UltraDry INTX-10P-A system equipped with Pathfinder. Each point of analysis was collected with an acceleration voltage of $20 \mathrm{kV}$ and live time of $30 \mathrm{~s}$.

\subsubsection{XRD measurements}

XRD analysis was obtained by a diffractometer Rigaku Ultima IV. XRD pattern was collected using as excitation the $\mathrm{Cu}-\mathrm{K} \alpha(40 \mathrm{KV}, 40 \mathrm{~mA})$, varying the angle $\theta$ in the range $10^{\circ}-70^{\circ}$ with resolution of $0.1^{\circ} \mathrm{step} / \mathrm{s}$. By XRD was measured the pure powder without any exposure and pure powder after UV exposure. Powders were darkened superficially during the UV exposure, then shuffled and exposed again to UV in order to maximize the ratio between beta and alpha phases and to reach the threshold of detection limit typical for XRD technique (around 1\%). The obtained pattern was analyzed by EVA database in order to identify all the phases present in the starting material.

\subsubsection{Pump-probe measurements}

For transient absorption measurements a train of laser pulses obtained by a regenerative Ti:Sapphire amplifier Coherent Libra-F-1K-HE230 to produce 100 -fs pulses at $800 \mathrm{~nm}$ with a $\mathrm{kHz}$-repetition rate. The train of laser pulses is divided into two parts by a beam splitter, called pump and probe respectively.

The pump laser pulse is sent on an optical parametric amplifier (TOPAS-800-fs-UV-1) and finally focused not perpendicularly on the sample, after a chopper synchronized with the frequency of the source. The synchronized chopper $(500 \mathrm{~Hz}$ ) stops half of the incident pulses in alternate way so that half of the obtained spectra will not be affected by the pump pulse (pump off), while the remaining will be affected (pump on).

A white super-continuum pulse (probe) is formed by multifrequencies generated by a sapphire plate which also guarantees a sufficient stability and bandwidth flatness. The probe pulse, after passing a controlled delay line, is focused and sent on the sample in the same intersection area of the pump pulse. After the interaction with the sample, transmission signal is collected into the detection system (UltrafastSystems HELIOS-80000-UV-VIS-NIR coupled with a CCD camera). For every single step of the delay line, a single wavelength dispersed differential transmission spectrum is acquired, obtaining a time spectrogram which can provide information about the temporal dynamics of the energy levels depletion.

Transient absorption was obtained by using a $400 \mathrm{~nm}$ pump signal (deep blue, compatible with two photons excitation from Yu et al.) and studying the interaction with the white super-continuum probe signal. The pump-probe curves were obtained varying the pump power in a range between 0.200 and $0.600 \mathrm{~mW}$ and collecting the signal in the "short live" range (10 ps - resolution $0.02 \mathrm{ps)}$ and "long live" range (10 ns - resolution $0.1 \mathrm{~ns})$.

\subsubsection{Reflectance measurements and colorimetric parameters}

Reflectance measurements were performed by means of UV-Vis-NIR Agilent Technologies Cary 5000 spectrophotometer equipped with integrating sphere module. The reflection configuration at $10^{\circ}$ measures the diffuse reflection of the sample with respect to a reference sample which is considered to have a $100 \%$ reflectivity. A calibrated source Illuminant D65 was used to determine the reflectance spectra and for calculating the colorimetric parameters.

\section{Results and discussion}

\subsection{Structural analysis}

The XRD analysis of "pure" sample (Fig. S2) corresponds entirely to the phase $\alpha-\mathrm{HgS}$, down to the detection threshold of $0.8-1$ wt $\%$ typical for this technique. As shown in Fig. 1A, the presence of specific Clrelated compounds can be easily detected, being characterized by Raman fingerprints well separated from the ones of cinnabar (spectra of Cl-based compounds and metacinnabar were retrieved form RRUFF database, the one of cinnabar was measured on the relic reported in Fig. 1B). As reported by Frost et al. [35], cinnabar pertains to $D_{3 h}$ point group, with $2 \mathrm{~A}_{1}{ }^{\prime}$ Raman active modes, and $3 \mathrm{~A}_{2}{ }^{\prime \prime}+5 \mathrm{E}^{\prime}$ modes, which are both infrared and Raman active. The $\mathrm{A}_{1}$ Raman active modes are reported at 43 and $256 \mathrm{~cm}^{-1}$ and the $E^{\prime}$ modes at 72, 88, 108, 283 and 343 $\mathrm{cm}^{-1}$. Two unassigned bands were observed at 290 and $351 \mathrm{~cm}^{-1}$. According to Frost Raman spectra of $\mathrm{HgS}$ and other sulphide pigments may be conveniently divided into three sections namely: (a) the region centred upon $350 \mathrm{~cm}^{-1}$ where the stretching vibrations are observed (b) the region centred upon $250 \mathrm{~cm}^{-1}$ ascribed to the bending vibrations and (c) the region below $100 \mathrm{~cm}^{-1}$ assigned to the lattice modes. Among them, the bending vibration region appears as the most sensitive to detect cinnabar phase variation.

It is clear that to discuss vibrational features of $\alpha$ - and $\beta$ - $\mathrm{HgS}$ one should consider in particular the $250-280 \mathrm{~cm}^{-1}$ range, so that we focused our attention to this specific Regions Of Interest (ROI). Fig. 1C, showing the Raman spectrum of as-prepared pure sample, fully confirms the XRD results showing the vibrational features of pure $\alpha-\mathrm{HgS}$ phase (peaks at 253, 283 and $350 \mathrm{~cm}^{-1}$, the spectrum was recorded with the high-resolution system) [10]. For comparison, the figure also reports the spectrum of metacinnabar, where the three main vibrations are blue-shifted of about 5-7 $\mathrm{cm}^{-1}$. Beta-HgS spectrum, assumed as a reference, was retrieved from RRUFF database (ID R060950) [32], the powders being from natural crystals. Beside the blue-shift, the ratio between the areas of the two bands at about 250 and $280 \mathrm{~cm}^{-1}$ $\left(A_{250} / A_{280}\right)$ undergoes a marked variation, decreasing by a factor 2 in the metacinnabar case. It is worth noting that the Raman spectroscopy provides a detection threshold far exceeding the XRD one, easily reaching values lower than $0.1 \mathrm{wt} \%$ and down to $\mathrm{ppm}$ in few cases [36-38]. Based on this starting achievement, we performed UV exposure on a set of samples, both pure and intentionally doped with $\mathrm{Cl}$ at different concentration. The darkening effect is sizable, as shown by the image of the samples reported in inset of Fig. 2A where a comparison between the pre and post-treatment is shown for the pure sample case. In order to quantify the effective darkening of red color, Fig. 2A and B and delineate the reflectance spectra and the first derivative reflectance spectra of pure and $5 \mathrm{M}$ samples submitted to UV exposure. The large variation in the reflectance spectra upon sample irradiation is evidenced also by first derivative spectra, whose change is significative and better expresses the UV exposure effect. According to Gueli et al. we calculated in Table 1 the CIE $\mathrm{L}^{*}, \mathrm{a}^{*}, \mathrm{~b}^{*}$ coordinates and the total color variation $\Delta \mathrm{E}_{\mathrm{Lab}}$ extracted from reflectance spectra $[39,40]$. We also calculated the Chroma $C^{*}$ coordinates, with hue angle $h$, which also mark the color variation in cylindric coordinates. Chromatic variation can be observed in a color reconstruction reported in Fig. 2C-D-E.

With the help of high-resolution Raman spectroscopy, we studied the spectra obtained in order to find a first interpretation of the phenomenon. Fig. 3 proposes the experimental spectra, obtained with the highresolution system, and the related deconvolution curves (with Lorentzian functions) to estimate the phase change form cinnabar to metacinnabar. In particular, Fig. $3 \mathrm{~A}$ and $\mathrm{B}$ shows the spectra deconvolution operated on red and partially darkened pure sample respectively. A comparison with the portable system with excitation at $1064 \mathrm{~nm}$ and low resolution is also proposed (Fig. $3 \mathrm{C}$ and D). Spectral resolution plays a key role for determining the above-mentioned ratio $A_{250} / A_{280}$ correlated to the transition from cinnabar to metacinnabar and a detailed section concerning the error estimation deriving from the low- and highresolution experimental systems is proposed below (vide infra, section 3.5). In particular, the high-resolution system is able to better separate the contribution of the two bands and to distinguish the presence of two extra vibrational features around 280 and $350 \mathrm{~cm}^{-1}$ (the fitting procedure being performed with 5 and 3 Lorentzian bands in the high and 


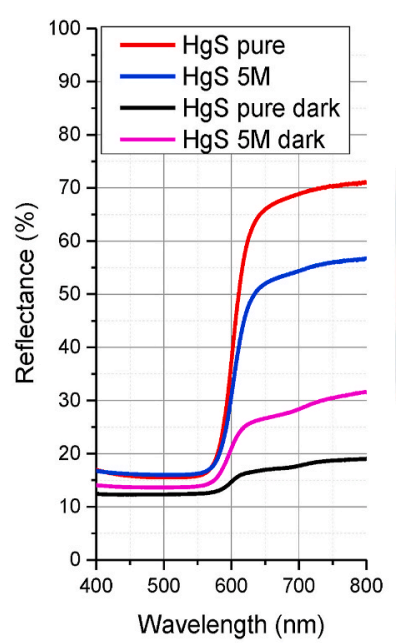

A

$\mathrm{C}$

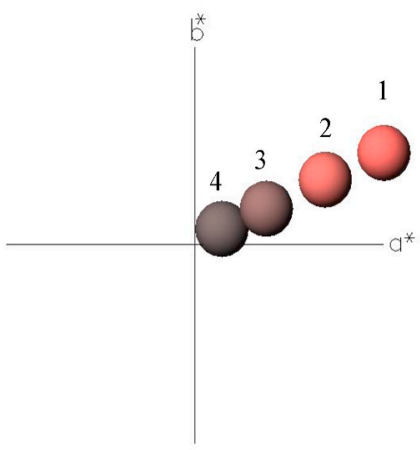

$\mathrm{D}$

\begin{tabular}{|ll|}
\hline 1 & PURE (No UV) \\
2 & $5 \mathrm{M}($ No UV) \\
3 & $5 \mathrm{M}(20 \mathrm{~h}$ UV exposed $)$ \\
4 & PURE (148 h UV exposed) \\
\hline
\end{tabular}

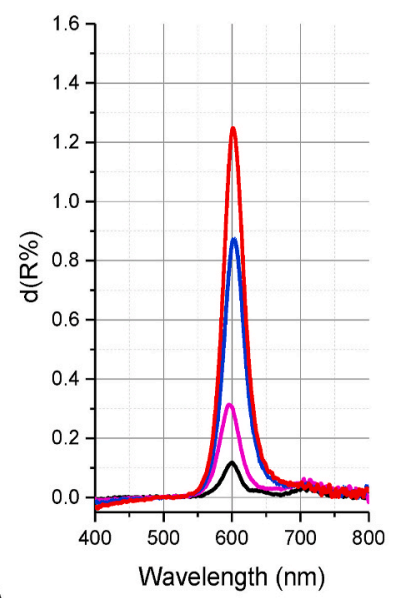

$\mathrm{B}$
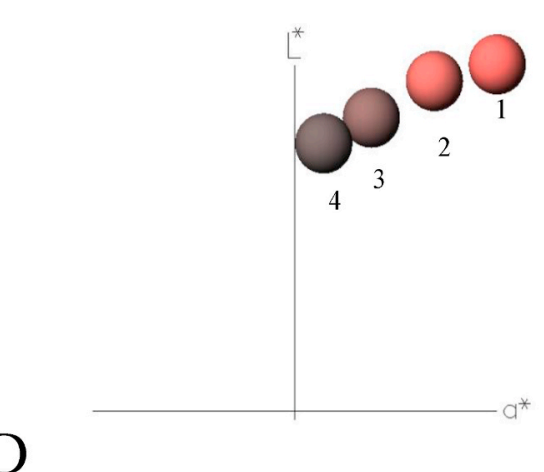

E

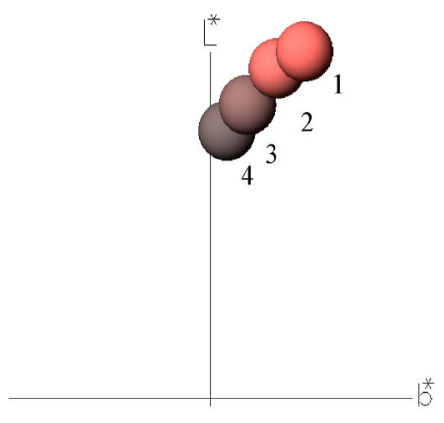

Fig. 2. Reflectance spectra and colorimetric parameters. Reflectance spectra of sample "pure" and $5 \mathrm{M}$ before and after UV exposure $\left(\lambda=365 \mathrm{~nm} ; 10 \mathrm{~mW} / \mathrm{cm}^{2}\right)(\mathbf{A})$; The inset show the darekend surface of "pure" sample after UV treatment. First derivative of Reflectance spectra (B); Variation of L*a*b* coordinates calculated from reflectance spectra (C-E).

Table 1

Chromatic coordinates variations calculated for samples $5 \mathrm{M}$ and Pure.

\begin{tabular}{lllllll}
\hline & Pure & Pure dark & $\Delta$ & $5 \mathrm{M}$ & $5 \mathrm{M}$ dark & $\Delta$ \\
\hline $\mathbf{L}^{*}$ & 55.74 & 43.05 & -12.69 & 53.06 & 47.19 & -5.87 \\
$\mathbf{a}^{*}$ & 34.18 & 4.89 & -29.29 & 23.58 & 12.92 & -10.66 \\
$\mathbf{b}^{*}$ & 15.84 & 2.75 & -13.09 & 11.24 & 6.22 & -5.02 \\
$\mathbf{\Delta E}_{\text {Lab }}$ & & & 34.50 & $\mathbf{\Delta \mathbf { E } _ { \text { Lab } }}$ & & 13.16 \\
& & & & & & \\
& & & $\boldsymbol{\Delta}$ & & & $\boldsymbol{\Delta}$ \\
$\mathbf{C}^{*}$ & 37.67 & 5.61 & -32.06 & 26.12 & 14.34 & -11.78 \\
$\mathbf{H}$ & 24.86 & 29.35 & 4.49 & 25.49 & 25.71 & 0.22 \\
\hline
\end{tabular}

low-resolution systems). However, it is important to pinpoint that within the estimated uncertainty, both the systems are able to detect the variation induced by light exposure (see Table SI). This is of outmost importance since the portable low-resolution system is a setup that can be successfully exploited to analyze ancient samples which cannot be moved out of the conservation site, as we verified in the present work on the ancient manuscript.

Extending our analysis to the other samples, we propose in figure Fig. 4A and Fig. S3 a comparison between the reference spectra of cinbefore and after UV treatment. In the samples with low $\mathrm{Cl}$ concentration we do not observe any band typically ascribed to chlorine-based compounds (wavenumber region below $200 \mathrm{~cm}^{-1}$ ), and the curves show a broadening of the band at $250 \mathrm{~cm}^{-1}$ (more accentuated in $5 \mathrm{M}$ sample) accompanied with a shift toward low wavenumbers. Furthermore, the intensity ratio between the band at $253 \mathrm{~cm}^{-1}$ and the shoulder at 283 $\mathrm{cm}^{-1}$ is completely different in samples submitted to UV exposure as compared to the pure one. This trend is compatible with the transformation from cinnabar to metacinnabar phase and is reported in the nabar and metacinnabar with those obtained for pure and $5 \mathrm{M}$ sample 
A

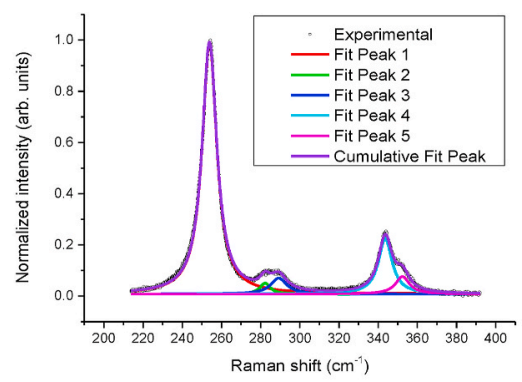

$\mathrm{C}$

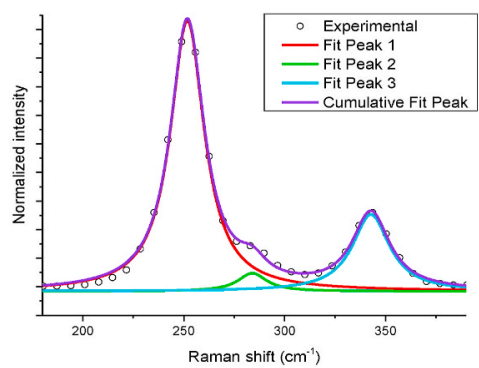

B

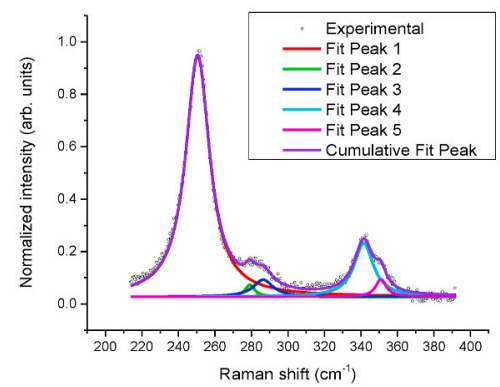

D

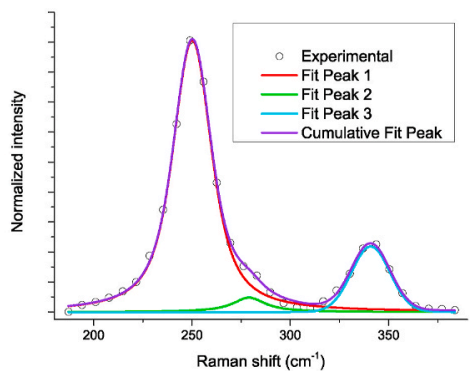

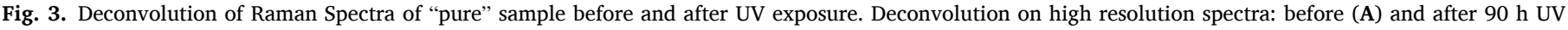
exposure (B); Deconvolution on low resolution spectra: before (C) and after UV exposure (D).

whole set of $\mathrm{Cl}$ doped samples. In addition, in the $5 \mathrm{M}$ sample a very weak broad band below $200 \mathrm{~cm}^{-1}$ is detected, suggesting the formation, at this $\mathrm{Cl}$ concentration level, of amorphous chlorine-based compound. $\mathrm{Cl}$ concentration appears as a crucial parameter: indeed, the $\mathrm{Cl}$ compound related vibrational band below $200 \mathrm{~cm}^{-1}$ is not observed in low $\mathrm{Cl}$ concentration samples, confirming the role of $\mathrm{Cl}$ dopant in elevated concentration. When we consider the darkening effect caused by UV exposure, we find that $\mathrm{Cl}$ impurities carry out a sort of catalytic action promoting a faster darkening of the UV exposed sample: whilst a complete degradation of the pigment is obtained after $148 \mathrm{~h}$ of light

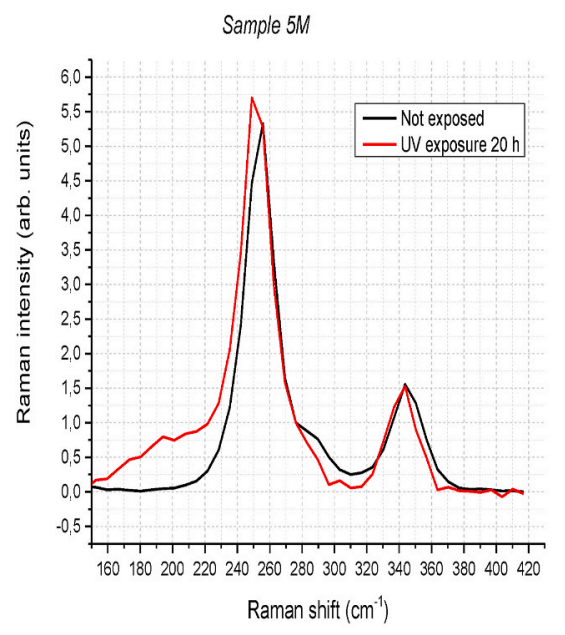

A exposure in the pure sample, darkening is achieved in only $20 \mathrm{~h}$ of exposure for the $5 \mathrm{M} \mathrm{Cl}$ doped sample. Further UV irradiation does not affect the sample, no additional variations in Raman spectra, reflectance measurements and chromatic coordinates being recorded.

\subsection{Cinnabar transition and metallic $\mathrm{Hg}$}

Raman spectroscopy was successfully applied to discriminate the contribution of $\mathrm{Cl}$ impurities to the darkening phenomenon under $\mathrm{UV}$ exposure, being able to display the cinnabar to metacinnabar transition

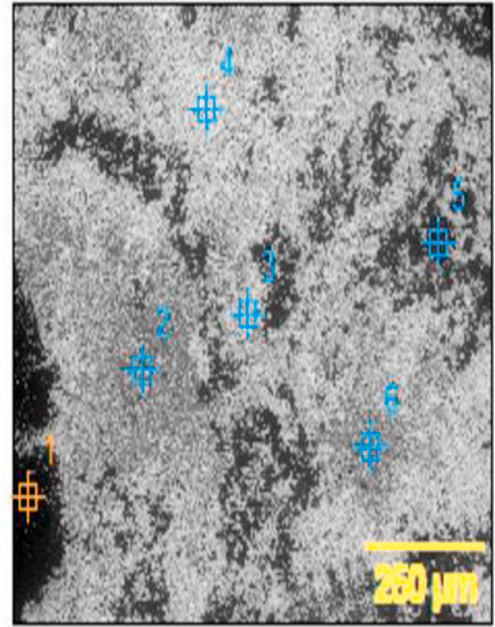

B

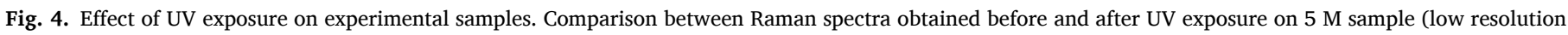

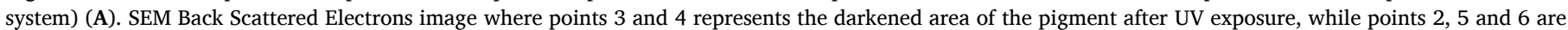
related to not darkened pigment. Point 1 concerns the glass slide (B). 
somehow accelerated by the presence of $\mathrm{Cl}$ ions. However, beside the chlorine-based compounds observed in the high $\mathrm{Cl}$ concentration case, we could not exclude the presence of other species which could also have a catalytic effect and could be not easily detected by Raman spectroscopy. This is the case of metallic $\mathrm{Hg}$, as already reported in the introduction [10]. To deepen this topic, we performed SEM measurements and elemental EDS analysis on the $5 \mathrm{M}$ UV darkened sample (Fig. 4B). The sample image gathered by back scattered electrons is reported on a grey scale correlated to the atomic weight of the elements. Table 2 summarizes the elemental results for the collected points indicated in Fig. 4B. By excluding the glass slide contribution, stoichiometric ratios among the elements imply the presence of $\mathrm{HgS}$ and $\mathrm{NaCl}$ starting compounds even after UV exposure. Other phases based on $\mathrm{Cl}$ species, like calomel or terlinguaite, are excluded for stoichiometric reasons. In addition, this analysis, which presents an excess of $\mathrm{Hg}$ not saturated with other elements, calls for the expected formation of metallic $\mathrm{Hg}$ in the darkened area. Table 2 reports also which points are related to "UV" and "No UV" area. In relation to these areas the ratio between atomic percentages of $\mathrm{Hg}$ and $\mathrm{S}$ (es. between points 3 or 4 and 2 or 5 or 6 in $5 \mathrm{M}$ sample) evidences a larger amount of $\mathrm{Hg}$ as compared to $\mathrm{S}$ especially in dark points, suggesting the presence of metallic $\mathrm{Hg}$. Although EDS analysis provide a specific elemental composition of the samples, it is not able to discriminate the exact phase of possible formed compounds, thus showing the need of a multi-technique approach to tackle the darkening issue. However, the comparison of the compounds determined for pure and $5 \mathrm{M}$ samples (Table 2), highlights once more the role of $\mathrm{Cl}$ impurities in promoting $\mathrm{HgS}$ phase transition down to the dissociation of $\mathrm{HgS}$ into metallic $\mathrm{Hg}$.

The transition from cinnabar to metacinnabar phase was recently validated by ultra-fast transient absorption measurements [10]. We performed spectrally resolved experiment on "pure" and "UV darkened pure" samples to discriminate the presence of each phase by their different excited state kinetics. Thanks to the spectral dispersion of our experiment, we observed a transient positive signal in the range between 750 and $800 \mathrm{~nm}$, and a negative signal in a broad band around 450-550 $\mathrm{nm}$ (Fig. 5A). According to Yu et al. positive signals of two-photons absorption (TPA) and excited-state absorption (ESA) are associated to pure red $\alpha$-HgS phase and to an intermediate state (chemical or structural phase) occurring during the phase transition from $\alpha$ to $\beta-\mathrm{HgS}$. Due to the lower frequency sampling of our experiment we could not isolate the contribution of pure cinnabar, but we detected its presence coupled to the intermediate state once a threshold power of about $0.450 \mathrm{~mW}$ was achieved, confirming previous results. The negative ground state depletion (GSD) signals, despite a larger time scale up to ns, seem to be compatible with the interpretation of Yu et al. indicating a short-lived GSD associated to $\beta$-Hgs phase and a long-lived GSD ascribed to metallic $\mathrm{Hg}$. Without further entering the details of the transient absorption kinetics, which will be the subject of a next work, the figure shows all the elements of the darkening transition, starting from TPA + ESA ( $\alpha$-HgS + transition phase), ESA (transition phase), short GSD
( $\beta-\mathrm{HgS})$ and finally long GSD (metallic $\mathrm{Hg}$ ).

The UV exposure proceeds from the surface of the cinnabar powders because of the large UV absorption and the very small penetration depth (the absorption gap of $\mathrm{HgS}$ is $2.1 \mathrm{eV}$ - [41]). To finally demonstrate the transition from $\alpha$-HgS to $\beta$-HgS we carried out a prolonged UV exposure experiment in order to achieve a darkened sample where the amount of $\beta$-HgS reached the sensitivity level of XRD measurements. The conclusive demonstration is given by the XRD pattern shown in Fig. 5B where the main diffraction peak of $\alpha-\mathrm{HgS}$ around $31^{\circ}$ shows the appearance of a shoulder towards lower angles because of the formation of $\beta$ - HgS [10]. These findings are in good agreement with the results gathered from pure alpha and beta cinnabar (the latter produced by thermal treatment, as reported in the introduction) and the ones obtained analyzing the effect of UV exposure [2,10].

To sum up the whole set of experimental results, we were able to highlight the transition from $\alpha-\mathrm{HgS}$ to $\beta$-HgS under UV exposure of samples eventually doped with $\mathrm{Cl}$ ions by means of a multi-technique approach. Among the others, thanks to its high sensitivity and nondestructive character, Raman spectroscopy is, in our opinion, the technique of election to examine in detail the kinetics of the darkening process allowing to discriminate the two phases as a function of the composition of the samples or the UV exposure undergone by them. Thus, a kinetic model based on the vibrational features is proposed to evaluate the darkening phenomenon in laboratory samples and some artbooks to assess conservation status and aging of the relics.

\subsection{The model}

As reported in the previous sections, the Raman spectra analysis and the darkening effect as a function of UV exposure and composition can be rationalized considering the phase transformation from cinnabar to metacinnabar as the main cause of the darkening process. The gathered results indicate that the effect is promoted by the presence of chlorine ions, but high concentration of this element produces the formation of other $\mathrm{Cl}$ related compounds (like corderoite, terlinguaite etc.). This interpretation is confirmed by recent studies proposing, in addition, the formation of metallic $\mathrm{Hg}$ as a possible darkening agent [2,9,10]. The role of chlorine is commonly accepted as catalyst, in presence of light, toward the formation of transition compounds. Several studies show how a phase transformation takes place with the help of coalescence phenomena where clusters of the new phase act as further nucleation center. This condition implies an exponential speed of transformation until the complete saturation, where chlorine impurities, or metacinnabar clusters engage the reaction as catalysts. Thus, we can assume the model of auto-catalyst reaction where the reaction products act as catalyst for a new step of the reaction and we apply The Verhulst model, based on logistic function [42-44]. By assuming $P$ as the measure of a species population and $t$ the time, the growth logistic model is defined by the differential eq. (1):

Table 2

EDS analysis of samples $5 \mathrm{M}$ and Pure.

\begin{tabular}{|c|c|c|c|c|c|c|c|c|}
\hline \multirow[t]{2}{*}{ Element } & \multirow{2}{*}{$\frac{\text { Glass slide (at } \%)}{\text { Point } 1}$} & \multicolumn{5}{|l|}{ Sample $5 \mathrm{M}$ (at \%) } & \multicolumn{2}{|c|}{ Sample Pure (at \%) } \\
\hline & & Point 2 (No UV) & Point 3 (UV) & Point 4 (UV) & Point 5 (No UV) & Point 6 (No UV) & Point 1 (at \%) & Point 2 (at $\%$ ) \\
\hline C & 13.63 & 27.78 & 17.69 & 17.00 & 11.00 & 20.55 & 17.83 & 16.83 \\
\hline $\mathbf{O}$ & 48.72 & 13.06 & 25.84 & 22.71 & 48.30 & 14.14 & 36.84 & 45.79 \\
\hline $\mathrm{Na}$ & 7.16 & 22.67 & 7.02 & 5.95 & 7.29 & 20.85 & 4.63 & 6.37 \\
\hline Mg & 1.57 & 0.38 & 1.15 & 0.97 & 1.81 & 0.45 & 1.00 & 1.06 \\
\hline Al & 0.39 & 0.07 & 0.35 & 0.39 & 0.53 & 0.21 & 0.42 & 0.40 \\
\hline $\mathrm{Si}$ & 20.31 & 2.55 & 5.61 & 4.55 & 19.99 & 3.26 & 13.32 & 14.82 \\
\hline$S$ & 1.77 & 5.73 & 14.62 & 17.84 & 3.07 & 8.71 & 10.48 & 5.74 \\
\hline $\mathrm{Cl}$ & 1.60 & 21.03 & 5.44 & 4.95 & 1.71 & 21.25 & 0.83 & 0.76 \\
\hline $\mathbf{K}$ & 0.43 & 0.07 & 0.04 & 0.06 & 0.41 & 0.08 & 0.20 & 0.29 \\
\hline $\mathrm{Ca}$ & 2.30 & 0.29 & 0.47 & 0.38 & 2.19 & 1.41 & 1.60 & 2.29 \\
\hline $\mathrm{Hg}$ & 2.12 & 6.36 & 21.75 & 25.21 & 3.70 & 9.09 & 12.85 & 5.63 \\
\hline
\end{tabular}


A
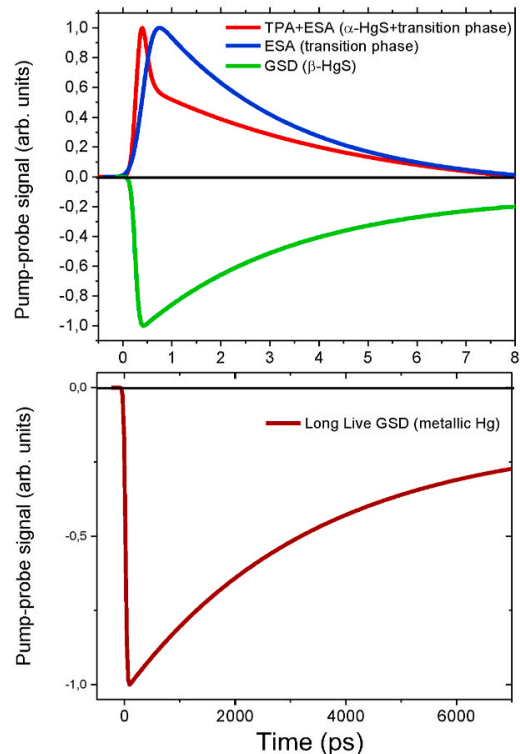

B

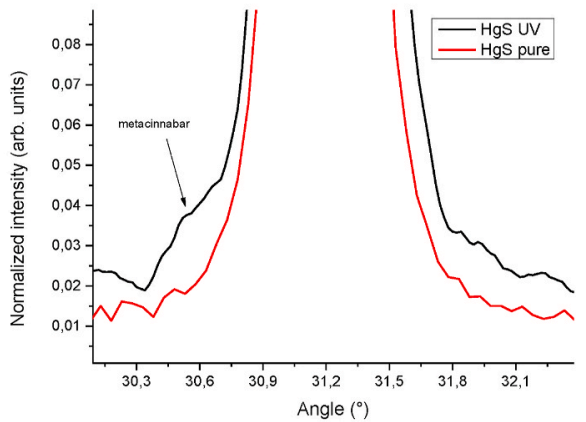

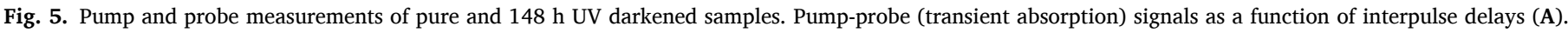

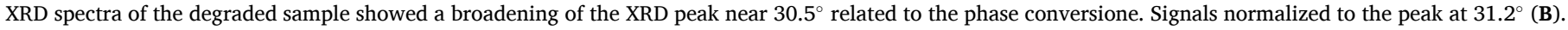

$\frac{d P}{d t}=k P\left(1-\frac{P}{K}\right)$

where $K$ is the asymptotic term at $t \rightarrow \infty$, the ratio $P / K$ represents the slowdown factor of the curve and $k$ refers to the growth rate. Equation (1) can be solved with the logistic function:

$P(t)=\frac{K}{1+q e^{-k t}}$

with

$q=\frac{K-P(0)}{P(0)}$

being the term $\mathrm{P}(0)$ the population at $\mathrm{t}=0$.

In our case, the asymptotic term $\mathrm{K}$ is 1 , since we have the complete transformation of the initial population ( $\alpha$-cinnabar) into the final one ( $\beta$-cinnabar). Thus, the model used in this study can be simplified accordingly

$P(t)=\frac{1}{1+q e^{-k t}}=\frac{1}{1+q e^{-\frac{t}{\tau}}}$

To apply the Verhulst model to the Raman spectra collected on synthetic samples, we need to find an observable representing cinnabar population at time $t$. We can focus the attention on the term $\mathrm{R}=\mathrm{A}_{252}$ / $\mathrm{A}_{283}$ representing the ratio between the areas of the bands at $252 \mathrm{~cm}^{-1}$ and $283 \mathrm{~cm}^{-1}$. As previously observed, this ratio changes when a phase transformation from cinnabar to metacinnabar is taking place. If we consider as $\mathrm{R}(0) \propto[\alpha-\mathrm{HgS}]$ the ratio at the time $\mathrm{t}=0$ when only the cinnabar phase is present and $\mathrm{R}(\mathrm{t}) \propto[\alpha-\mathrm{HgS}]+[\beta-\mathrm{HgS}]$ the ratio due to contemporary presence of cinnabar and metacinnabar, the normalized ratio $R_{n}$ expresses the fraction of $[\beta-\mathrm{HgS}]$ with respect to the total composition according to the following relation:

$R_{n}=\frac{R(t)-R(0)}{R(t)}=\frac{[\beta-H g S]}{[\alpha-H g S]+[\beta-H g S]}$

By equalizing eq. (5) with eq. (4), the population $\mathrm{P}(\mathrm{t})$ of $[\beta-\mathrm{HgS}]$ can be expressed by the following relation:
$P(t)=R_{n}=\frac{R(t)-R(0)}{R(t)}=\frac{[\beta-H g S]}{[\alpha-H g S]+[\beta-H g S]}=\frac{1}{1+q e^{-\frac{t}{t}}}$

where, according to the logistic model, the following conditions hold:

$\lim _{t \rightarrow 0} R_{n}=0=[\alpha-H g S]$

$\lim _{t \rightarrow \infty} R_{n}=1=[\beta-H g S]$

The term $\tau$ of the equation is defined as the characteristic time of the reaction during the darkening process. According to the literature, it depends on a large set of factors governing the pigment degradation: relative humidity $(\mathrm{RH})$, chlorine concentration $([\mathrm{Cl}])$, temperature (considered in terms of activation energy $\mathrm{E}_{\mathrm{kT}}$ ), metacinnabar concentration ([ $\beta$-HgS $]$ ), light exposure (both in terms of light energy $\mathrm{E}_{\mathrm{h} \nu}$ and exposure time $t_{\text {exp }}$ ). To complete the darkening model it is therefore mandatory to study the characteristic time $\tau=\tau\left(R H, E_{k T}, E_{h \nu},[C l],[\beta-H g S], t_{\text {exp }}\right)$ to understand the role of the different factors.

\subsection{Logistic model applied to synthetic samples}

By operating a deconvolution with Lorentzian functions on the Raman spectra, we calculated the ratio $\mathrm{R}(\mathrm{t})$ and $\mathrm{R}(0)$ as a function of $\mathrm{UV}$ exposure time for each synthetic sample. A complete extraction procedure with deconvolution functions is reported into the supplementary materials. Based on the results reported in section 3.1, we pursued the analysis on the synthesized samples with the low-resolution system to validate the approach for the investigation of ancient relics (considered in section 3.6). Fig. 6 reports the experimental points obtained for any sample and the logistic fit of eq. (6). The figure summarizes also the fitting parameters $K, q$ and $\tau$ (we leave the parameter $K$ free to verify that its value is equal to 1 , as previously discussed). Error bars are obtained by using the spectrometer sensitivity and standard deviation associated to each determined area.

As perceived from the data, the characteristic time $\tau$ decreases drastically as a function of $\mathrm{Cl}$ concentration. This insight confirms again the key role played by Chlorine during the process and the observed 
A

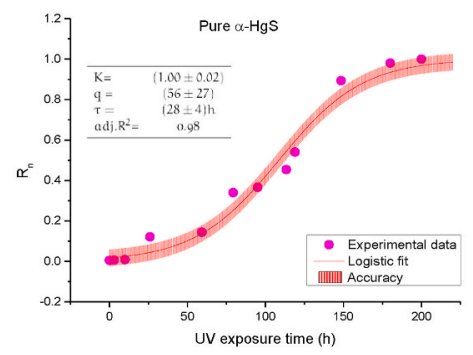

C

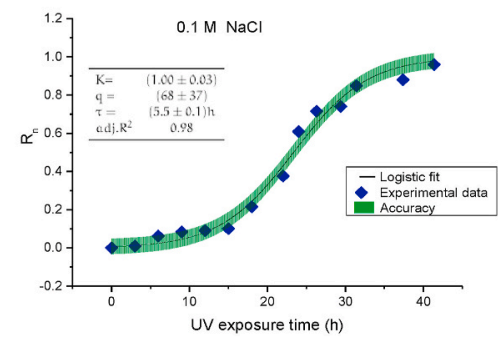

$\mathbf{E}$

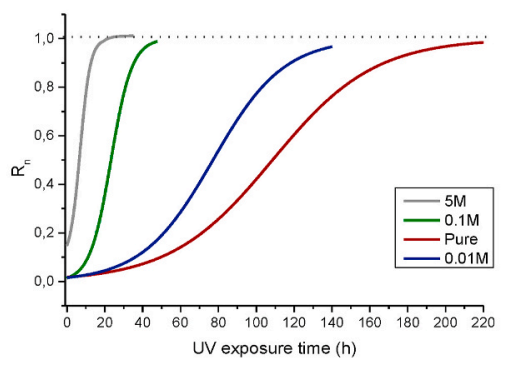

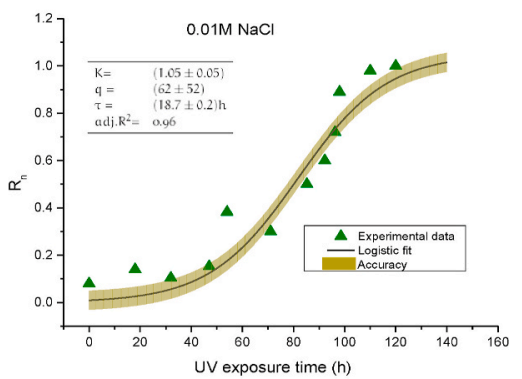

D

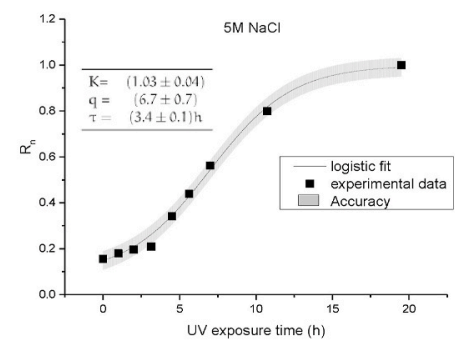

F

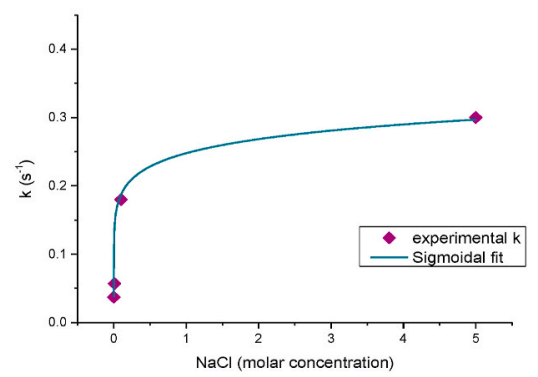

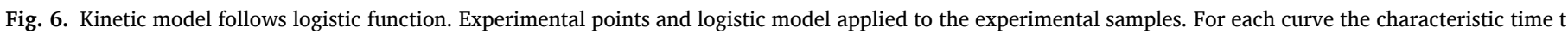

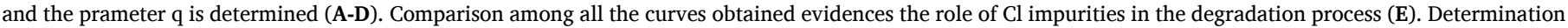

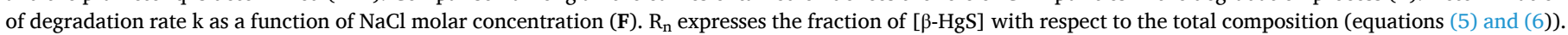

catalytic effect of the ion. It is also worth noting that $\mathrm{K}$ value is equal to 1 in the whole set of samples, as expected. However, albeit the value of the parameter $q$ is quite homogeneous for the first three samples, the $5 \mathrm{M}$ one shows a large decrease of the q value. Since q represents the percentage of $\beta-\mathrm{HgS}$ at time $\mathrm{t}=0$, we get from eq. (3) that the first three samples have the same starting concentration of metacinnabar of about $1.5-2 \%$. As for the sample $5 \mathrm{M}$ we have already noted that the Raman spectrum displays an additional band at about $270 \mathrm{~cm}^{-1}$ due to the presence of chlorine-based compounds formed during the reaction, as mentioned before. Thus, a deconvolution with only two Lorentzian bands at $283 \mathrm{~cm}^{-1}$ and $255 \mathrm{~cm}^{-1}$ did not lead to an acceptable fit and a third Lorentzian band must be considered to successfully fit the data. The most suitable compound forming an additional band in the region of interest for our deconvolution is calomel, which is characterized by a vibrational mode at $273 \mathrm{~cm}^{-1}$ [28]. Therefore, the ratio $R_{n}$ is corrected in order to consider the contribution of this additional band:

$R_{n}=\frac{R(t)-R(0)}{R(t)_{T O T}}$

with

$R(t)_{T O T}=\frac{A_{255}}{A_{283}+A_{273}}$
Assuming this correction, one can validate the model considering the two extreme cases, $t \rightarrow 0$ where no contribution of calomel is observed and the ratio $\mathrm{R}_{\text {TOT }}=\mathrm{R}$, whilst for $t \rightarrow \infty$ the products of the reaction are composed by a mixture of calomel and metacinnabar. This assumption justifies a very low value of q parameter (6.7) for $5 \mathrm{M}$ sample which corresponds to a high concentration of reactive products even at $t=0$. Indeed, in Fig. 4E the curve presents an initial R (0) parameter of 0.15 , corresponding to $15 \%$ of possible mixture calomel + metacinnabar. A reasonable justification of this value originates from the high concentration of chlorine ions which could cause an initial transformation of cinnabar even without light exposure. Fig. 6E summarizes the curves obtained for each sample as a function of the UV exposure time and $\mathrm{Cl}$ concentration. In addition, we studied the variation of the rate $k$ expressed in eq. (1) as a function of $\mathrm{Cl}$ concentration (Fig. 6F). A sigmoidal fit, derived solving the logistic function with $k$, suggests that 5 $\mathrm{M}$ concentration is a saturation value and higher content of chlorine does not produce drastic effects on the speed of darkening process.

\subsection{Error analysis}

An estimation of errors associated to this model can be determined considering a linear propagation of relative uncertainties of each parameter present in equation (5). As evidenced in our model, the ratio $R_{n}$ derives from the ratios $R(t)$ and $R_{0}$ which, analogously, depend on the 
ratio $A_{250} / A_{280}$. Consequently, due to the fitting procedure operated for determining the areas $A_{250}$ and $A_{280}$, we estimated a variation of the relative error $\Delta R_{n} / R_{n}$ in relation to experimental resolution as follows:

- $0.2<\frac{\Delta R_{n}}{R_{n}}<0.4$ with resolution $8 \mathrm{~cm}^{-1}$;

- $0.04<\frac{\Delta R_{n}}{R_{n}}<0.06$ with resolution $0.2 \mathrm{~cm}^{-1}$

Lowest values are determined when $R_{n} \rightarrow 0$, while highest values when $R_{n} \rightarrow 1$. In Fig. 7A we reported a comparison between the two experimental resolutions and a comparison of the relative error as a function of the selected grating of the system (Fig. 7B). This analysis confirms once again, and through the whole range of UV exposure examined, that the results obtained with the low-resolution system are in very good agreement with the ones gathered with the high-resolution system, further supporting the exploitation of the former in the analysis of precious relics.

\subsection{Logistic model applied to ancient samples}

The logistic model (eq. (3)) was empirically applied to the set of ancient samples belonging to BUCA with the intent to study if the
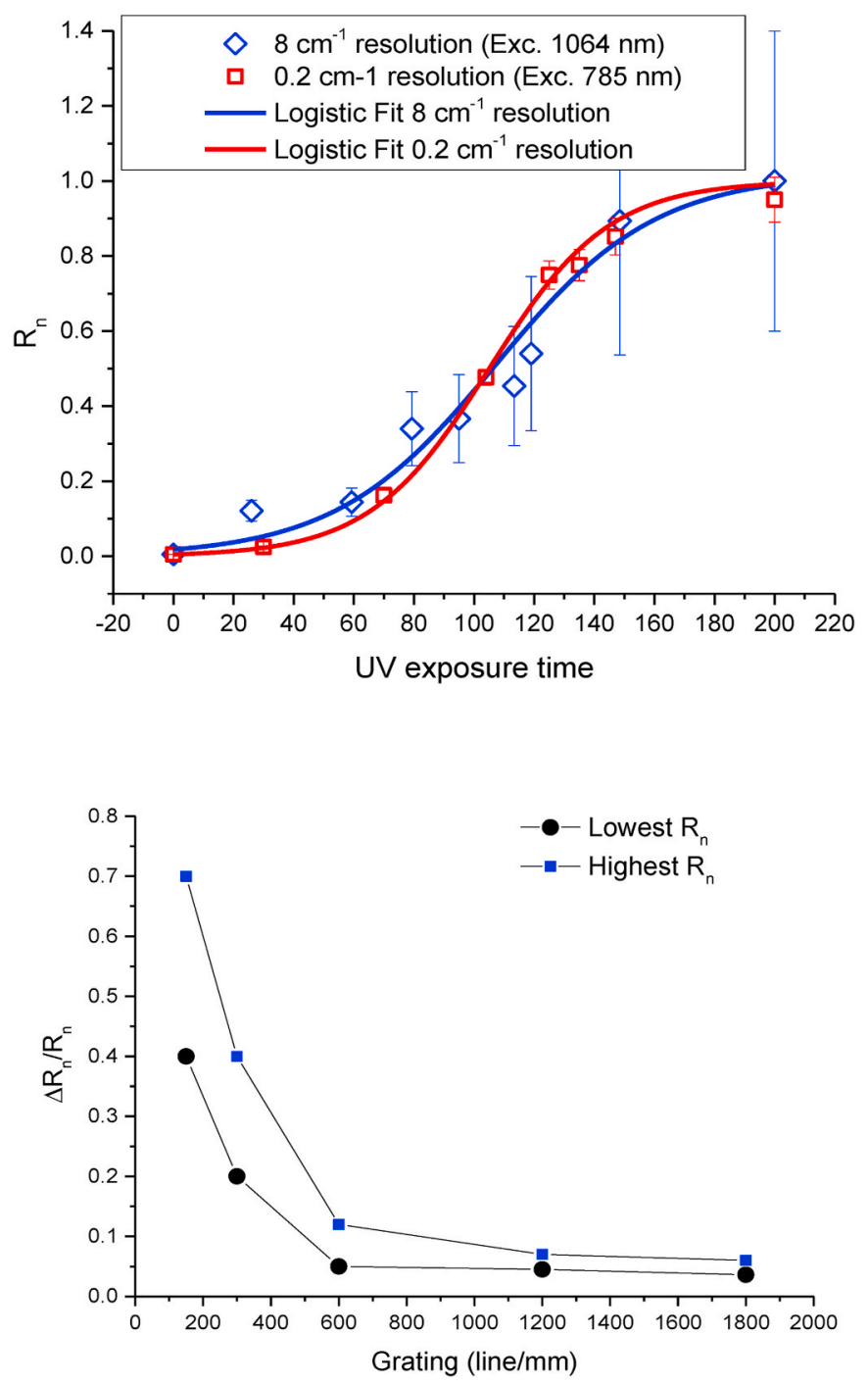

Fig. 7. Error estimation in relation to experimental resolution. Comparison of $R_{n}$ values and error bars obtained with experimenal systems with $8 \mathrm{~cm}^{-1}$ and $0.2 \mathrm{~cm}^{-1}$ resolution (A). Relative error of $\mathrm{R}_{\mathrm{n}}$ as a function of grating characteristics. analysis developed for synthetic samples can be exploited for natural aging. Operating in this way, we did not exclude that the spectra of ancient samples can be affected by a number of factors, such as impurities, natural variation, spatial variation, unknown environmental conditions since the creation, beside light irradiation. However, we know the date of the ancient samples, and we could test the model on these samples by assuming standard conservation conditions, such as temperature, RH or light exposure, as previously done in a work dealing with paper relics [26]. Indeed, the overlay procedure of results on synthetic samples and historical artworks is absolutely empirical. It was a tentative approach to verify if the model studied on synthetic samples could be applied to study ancient samples. We exploit the synthetic cinnabar as time zero reference for the aging curve reported in Fig. S4, where the concentration of metacinnabar is plotted versus the age of the relics produced in the 1435-1511 A.D. range. In Fig. S4 we also reported the experimental average spectra gathered on the artworks of BUCA, to show that very small differences were recorded in those samples (as also shown in Fig. 8B). The whole set of samples but the third one (Libri Sententiarum - indicated as red in the plot), agree very well to the fit model, despite the short time range explored. As for the Libri Sententiarum sample, it should be noted that the writing date of this copy is affected by a large uncertainty. As evidenced by the curve the parameter $\tau$ associated to the characteristic time of degradation is estimated in 100 years. The accuracy of the fit covers all the experimental points, or their error bars, within the range of $8 \%$. It is worth nothing that, as discussed before, the uncertainty associated to fitting curve takes into account the effects of impurities, natural variation, spatial variation, unknown environmental conditions since the creation (other colorants were not considered because they were not revealed by Raman spectroscopy). The spread associated to experimental points in Fig. S4 evidences this aspect. However, despite that, there is a good agreement with the fitting curve and the experimental data gathered on ancient samples.

To extend the time range explored, we applied the model directly to other Raman spectra extracted from the literature, by collecting spectra of samples belonging to XIII-XVII centuries (Fig. 8B). Since we had not enough information about the effective date of production from literature, but only a generic indication of the centuries, we hypothesized an error bar of 50 years, thus reporting in the figure three point for each literature sample, to account for beginning, middle and end of the correspondent century. We can observe that the model reproduces the experimental data with an $8 \%$ accuracy (as the one obtained for the BUCA samples) when considering the first half of the century as the manufacturing date of the relics. This is in good agreement with other spectra reported in the literature [25,45-48].

\subsection{Correspondence between the model applied to natural and UV-caused darkening}

With the purpose of a complete application of the model, we can hypothesize a calibration of $\tau$ and q parameters. To achieve a correspondence between synthetic and experimentally UV-caused darkening of the cinnabar, we calculated the equivalence ratio of the two parameters as follows:

$\tau_{\text {eq }}=\frac{\tau_{\text {ancient }}}{\tau_{\text {pure }}}$

$q_{\text {eq }}=\frac{q_{\text {ancient }}}{q_{\text {pure }}}$

where with the subscript ancient we refer to the fit parameters recovered in the artbook analysis. The conversion will be obtained, in the case of sample $5 \mathrm{M}$ for example, by using the recalculated parameters with the formula:

$\tau_{\text {calibrated }_{5 M}}=\tau_{5 M} \cdot \tau_{e q}$ 
A

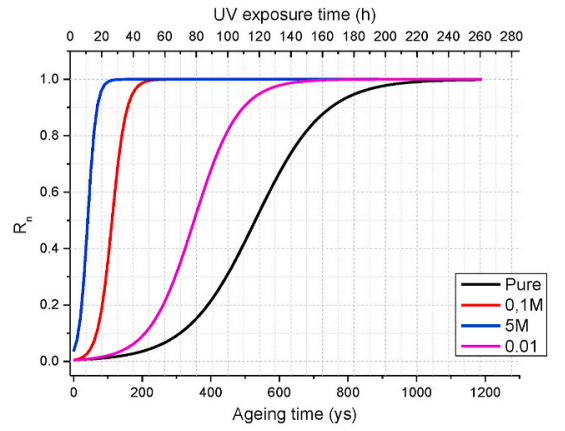

B

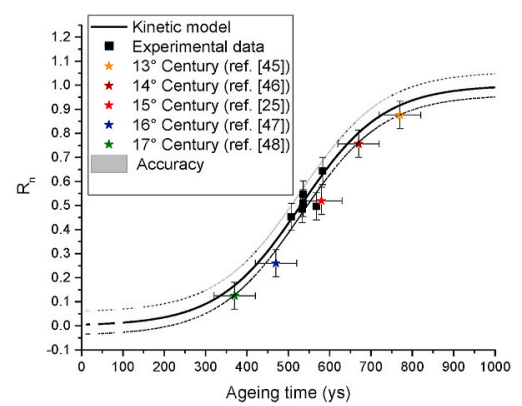

Fig. 8. Ageing model. Correlation between the UV exposure time (hours) and ageing time expressed in years (A). Validation of ageing model applied to literature data with an accuracy of $8 \%$ (B).

$q_{\text {calibrated }_{5 M}}=q_{5 M} \cdot q_{e q}$

The result is the following equation:

$P(t)=R_{n}=\frac{1}{1+q_{\text {calibrated }_{S M}} e^{-\frac{\bar{\tau}_{\text {calibrated }} M}{t}}}$

Fig. 8A reports all the curves calibrated for each sample in which the double scale indicates the conversion between natural darkening (years) and UV-accelerated process $(\mathrm{h})$. In the reported graph the correlation between the two process is evidenced, especially considering the role of the $\mathrm{Cl}$ impurities.

\subsection{Thermal treatments}

Finally, we want to consider the role of temperature in the darkening phenomenon. With the purpose of simulating the effect of the time as a thermodynamic process, we treated the $\mathrm{Cl}$-doped samples at high temperature in a home-made aging chamber. We first selected $75^{\circ} \mathrm{C}$ with $60 \%$ of Relative Humidity (normally used as aging standard in common processes according to ISO 5630-3) and treated the sample in a period ranging from 0 to 10 days [49]. We determined the $R_{n}$ ratio (that is the metacinnabar concentration) by collecting Raman spectra at fixed time interval $(12 / 24 \mathrm{~h})$. Under these experimental conditions no evident trend of $R_{n}$ value was recovered. Selecting the temperature at $200^{\circ} \mathrm{C}$ to drastically enhance the effect of the aging, we could not find clear indications because of a strong loss of samples weight. The mass loss was estimated of about $1 \%$ per hour for each sample. Indeed, we correlated the appearance of a volatile element to the possible formation of metallic $\mathrm{Hg}$, in agreement with SEM and transient absorption measurements previously reported. By performing specific EDS analysis for these samples (see table SII in Supplementary Materials) we can evidence the loss of $\mathrm{Hg}$ in relation to stoichiometric ratio with S. In fact, an excess of S in the compositional analysis suggests the partially dissociation of $\mathrm{HgS}$, formation of metallic $\mathrm{Hg}$ and its consequent evaporation [14].

We then selected an intermediate temperature of $135{ }^{\circ} \mathrm{C}$ and the $\mathrm{R}_{\mathrm{n}}$ trend evidenced in pure, $0.1 \mathrm{M}$ and $5 \mathrm{M}$ samples is reported in Fig. S5. Despite the mass loss recorded even at this temperature (see Table 3), we were able to measure the vibrational features over the whole aging period (10 days). As shown in the figure, whilst pure and $0.1 \mathrm{M}$ samples

Table 3

Stoichiometric balance of $\mathrm{Hg}$ compounds from data obtained in Table 1 .

\begin{tabular}{lll}
\hline \multicolumn{2}{l}{ Identified compound - SEM/EDS } \\
\hline & Dark area & Red area \\
\hline \multirow{2}{*}{ Pure } & Metallic Hg (3\%) & $\mathrm{HgS}$ \\
& $\mathrm{HgS}(10 \%)$ & $\mathrm{HgS}$ and metallic Hg (1.24\%) \\
& Metallic Hg (7\%) & \\
\hline
\end{tabular}

Table 4

Mass loss percentage due to the thermal treatment executed on the experimental samples.

\begin{tabular}{llll}
\hline$\%$ Mass loss per $\mathrm{h}$ & & & \\
\hline & Pure & $0.1 \mathrm{M}$ & $5 \mathrm{M}$ \\
\hline $135^{\circ} \mathrm{C}$ & $1.7 \%$ & $0.1 \%$ & $0.7 \%$ \\
$200{ }^{\circ} \mathrm{C}$ & $2 \%$ & $0.2 \%$ & $0.7 \%$ \\
\hline
\end{tabular}

present similar linear trend with very slow increasing of $R_{n}$ ratio, in the $5 \mathrm{M}$ sample the slope is larger, confirming the $\mathrm{Cl}$ concentration role already discussed (see Table 4).

\section{Conclusions}

This work proposes a kinetic model of red vermilion degradation by correlating the role of $\mathrm{Cl}$ impurities in the phase changing of cinnabar to metacinnabar. The study was addressed to a set of synthetic samples brought forth by the so-called wet method of vermilion production and doped with different chlorine concentrations. For having a complete understanding of the phenomenon, we also concentrated our attention to ancient manuscript samples belonging to XIII-XVII century. Our analysis conducted principally through Raman spectroscopy, but also with the help of XRD and SEM/EDS, reveals a transformation from the alpha-cinnabar phase to the dark beta-cinnabar with the contemporary presence of metallic Hg. The latter is also confirmed by pump-probe measurements which evidenced, in transient absorption measurements, a long-life ground state depletion recently assigned to metallic $\mathrm{Hg}$. The complete panorama of experimental results, in particular the Raman analysis, can be explained with a logistic trend of the darkening effect. In fact, following the model of auto-catalyst reaction and the Verhulst curve, we found the characteristic time $\tau$ for natural degradation and UV-accelerated process. We estimated natural $\tau$ of 100 years for pure cinnabar and we correlated it to the UV-accelerated $\tau$, estimated for different $\mathrm{Cl}$ impurities of the samples. The model addresses especially to the circumstances where light exposition and high environment salinity can activate the darkening process (frescos or mural painting exposed to natural agents). However, it is adaptable to all artifacts in which pure $\mathrm{HgS}$ or a low doping of $\mathrm{Cl}$ is present. Finally, this work evidenced, once again, the role of no-destructive portable techniques, like Raman spectroscopy able to provide important information on materials investigation applied to cultural heritage.

\section{Author contributions}

D.C. supervised the project, performed all experiments, analyzed and interpreted the data.; M.P. performed the experiments regarding the ancient texts; F.A.P. prepared the synthetic samples, performed the 
experiments regarding the synthetic samples and analyzed the data; G.C. selected the ancient texts and prepared their synthetic profiles; P.C.R. and C.M.C. performed all experiments and participated in data interpretation.

\section{Declaration of competing interest}

The authors declare that they have no known competing financial interests or personal relationships that could have appeared to influence the work reported in this paper.

\section{Acknowledgments}

All the authors acknowledge the fruitful collaboration with the staff of the Biblioteca Universitaria di Cagliari (BUCA), Sardinia. Their kind collaboration and expertise helped us during all the measurement sessions. The experimental measurements were performed under a convention between BUCA and the Physics Department of the University of Cagliari. The authors also thank S. Grillo for valuable assistance and discussions in the XRD analyses. We acknowledge the CeSAR (Centro Servizi Ricerca d'Ateneo) core facility of the University of Cagliari and Dr. M. Marceddu for assistance with the generation of transient absorption data.

\section{Appendix A. Supplementary data}

Supplementary data to this article can be found online at https://doi. org/10.1016/j.dyepig.2020.108866.

\section{References}

[1] Ballirano P, Botticelli M, Maras A. Thermal behaviour of cinnabar, $\alpha-\mathrm{HgS}$, and the kinetics of the $\beta$ - HgS (metacinnabar) - $\alpha$-HgS conversion at room temperature. Eur J Mineral 2014;25:957-65. https://doi.org/10.1127/0935-1221/2013/00252341.

[2] Elert K, Cardell C. Weathering behavior of cinnabar-based tempera paints upon natural and accelerated aging. Spectrochim Acta Part A Mol Biomol Spectrosc 2019. https://doi.org/10.1016/j.saa.2019.03.027.

[3] Barnett JR, Miller S, Pearce E. Colour and art: a brief history of pigments. Optic Laser Technol 2006. https://doi.org/10.1016/j.optlastec.2005.06.005.

[4] Carlyle L, Roy A. Artists' pigments: a handbook of their history and characteristics. J Am Inst Conserv 1996;2. https://doi.org/10.2307/3179938.

[5] Keune K, Boon JJ. Analytical imaging studies clarifying the process of the darkening of vermilion in paintings. Anal Chem 2005. https://doi.org/10.1021/ ac048158f.

[6] Radepont M, Coquinot Y, Janssens K, Ezrati JJ, De Nolf W, Cotte M. Thermodynamic and experimental study of the degradation of the red pigment mercury sulfide. J Anal At Spectrom 2015. https://doi.org/10.1039/c4ja00372a.

[7] Hogan C, Da Pieve F. Colour degradation of artworks: an ab initio approach to X ray, electronic and optical spectroscopy analyses of vermilion photodarkening. J Anal At Spectrom 2015. https://doi.org/10.1039/c4ja00327f.

[8] Davidson RS, Willsher CJ, Morrison CL. Influence of some solvents and solutes on illuminated red mercury(II) sulphide electrodes. J Chem Soc Faraday Trans 1 Phys Chem Condens Phases 1982. https://doi.org/10.1039/F19827801011.

[9] Miguel C, Pinto JV, Clarke M, Melo MJ. The alchemy of red mercury sulphide: the production of vermilion for medieval art. Dyes Pigments 2014. https://doi.org/ 10.1016/j.dyepig.2013.10.041.

[10] Yu J, Warren WS, Fischer MC. Visualization of vermilion degradation using pumpprobe microscopy. Sci Adv 2019. https://doi.org/10.1126/sciadv.aaw3136.

[11] Potter RW, Barnes HL. Phase relations in the binary Hg-S. Am Mineral; 1978.

[12] Dickson FW, Tunell G. The stability relations of cinnabaar and metacinnabar. J Mineral Soc Am 1959.

[13] Svensson M, Düker A, Allard B. Formation of cinnabar-estimation of favourable conditions in a proposed Swedish repository. J Hazard Mater 2006. https://doi. org/10.1016/j.jhazmat.2006.01.018.

[14] Dickson FW, Tunell G. The stability relations of cinnabar and metacinnabar. Am Mineral 1959.

[15] Feller RL. Studies on the darkening of vermilion by light. Rep Stud Hist Art 1967.

[16] Gettens RJ, Feller RL, Chase WT. Vermilion and cinnabar. Stud Conserv 1972. https://doi.org/10.1179/sic.1972.006.

[17] Daniels V. The blackening of vermilion by light. Recent Adv. Conserv. Anal. artifacts Jubil. Conserv. Conf. Pap. London 1987. 6-10 July 1987.

[18] Spring M, Grout R. The blackening of vermilion: an analytical study of the process in paintings introduction. Natl Gallery Tech Bull 2002. https://doi.org/10.1002/ col.5080050319.
[19] Anaf W, Janssens K, De Wael K. Formation of metallic mercury during photodegradation/photodarkening of $\alpha$-HgS: electrochemical evidence. Angew Chem Int Ed 2013. https://doi.org/10.1002/anie.201303977.

[20] Fernandes RF, de Oliveira LFC, Edwards HGM, Brooke CJ, Pepper M. Raman spectroscopic analysis of a belltower commemorative wall decoration. Appl Phys A Mater Sci Process 2017. https://doi.org/10.1007/s00339-017-0761-4.

[21] Colomban P. On-site Raman study of artwork: procedure and illustrative examples. J Raman Spectrosc 2018;49:921-34. https://doi.org/10.1002/jrs.5311.

[22] Chiriu D, Ricci PC, Scattini M, Polcaro A, D'Andrea M, Richard S, et al. Portable NIR Raman microspectroscopy investigation on early bronze IV pottery (2500-1950 BCE) from khirbat iskandar, Jordan. Vib Spectrosc 2018;97:8-15. https://doi.org/10.1016/j.vibspec. 2018.04.002.

[23] Chiriu D, Ricci PC, Carbonaro CM, Nadali D, Polcaro A, Mocci F. Drying oil detected in mid-third Millennium B.C. Mesopotamian clay artifacts: Raman spectroscopy and DFT simulation study. Microchem J 2016;124:386-95. https:// doi.org/10.1016/j.microc.2015.09.013.

[24] Chiriu D, Ricci PC, Cappellini G, Carbonaro CM. Ancient and modern paper: study on ageing and degradation process by means of portable NIR $\mu$-Raman spectroscopy. Microchem J 2018;138:26-34. https://doi.org/10.1016/j microc.2017.12.024.

[25] Chiriu D, Ricci PC, Cappellini G. Raman characterization of XIV-XVI centuries Sardinian documents: inks, papers and parchments. Vib Spectrosc 2017;92:70-81. https://doi.org/10.1016/j.vibspec.2017.05.007.

[26] Chiriu D, Ricci PC, Cappellini G, Salis M, Loddo G, Carbonaro CM. Ageing of ancient paper: a kinetic model of cellulose degradation from Raman spectra. J Raman Spectrosc 2018. https://doi.org/10.1002/jrs.5462.

[27] Bersani D, Madariaga JM. Applications of Raman spectroscopy in art and archaeology. J Raman Spectrosc 2012. https://doi.org/10.1002/jrs.4219.

[28] Dominguez-Vidal A, Jose De La Torre-Lopez M, Rubio-Domene R, AyoraCañada MJ. In situ noninvasive Raman microspectroscopic investigation of polychrome plasterworks in the Alhambra. Analyst 2012. https://doi.org/ 10.1039/c2an36027f.

[29] Xhaxhiu K, Saraçi E, Bente K. Sequestration of supercritical CO2 by mercury oxide. Chem Pap 2013. https://doi.org/10.2478/s11696-013-0356-2.

[30] Chukanov NV. Infrared spectra of mineral species. https://doi.org/10.100 7/978-94-007-7128-4; 2014

[31] Chukanov NV. IR spectra of minerals and reference samples data. https://doi.org/ 10.1007/978-94-007-7128-4_2; 2014.

[32] Lafuente B, Downs RT, Yang H, Stone N. The power of databases: the RRUFF project. Highlights Mineral. Crystallogr 2016. https://doi.org/10.1515/ 9783110417104-003.

[33] Neiman MK, Balonis M, Kakoulli I. Cinnabar alteration in archaeological wall paintings: an experimental and theoretical approach. Appl Phys A Mater Sci Process 2015. https://doi.org/10.1007/s00339-015-9456-x.

[34] Pouli P, Emmony DC, Madden CE, Sutherland I. Studies towards a thorough understanding of the laser-induced discoloration mechanisms of medieval pigments. J Cult Herit 2003. https://doi.org/10.1016/s1296-2074(02)01207-4.

[35] Frost RL, Edwards HGM, Duong L, Kloprogge JT, Martens WN. Raman spectroscopic and SEM study of cinnabar from Herod's palace and its likely origin. Analyst 2002. https://doi.org/10.1039/b109368c.

[36] Li B, Calvet A, Casamayou-Boucau Y, Morris C, Ryder AG. Low-content quantification in powders using Raman spectroscopy: a facile chemometric approach to sub $0.1 \%$ limits of detection. Anal Chem 2015. https://doi.org/ 10.1021/ac504776m.

[37] Vandenabeele P, Moens L. Some ideas on the definition of Raman spectroscopic detection limits for the analysis of art and archaeological objects. J Raman Spectrosc 2012. https://doi.org/10.1002/jrs.4055.

[38] Vandenabeele P, Jehlička J, Vítek P, Edwards HGM. On the definition of Raman spectroscopic detection limits for the analysis of biomarkers in solid matrices. Planet Space Sci 2012. https://doi.org/10.1016/j.pss.2011.12.006.

[39] Gueli AM, Bonfiglio G, Pasquale S, Troja SO. Effect of particle size on pigments colour. Color Res Appl 2017. https://doi.org/10.1002/col.22062.

[40] Gueli AM, Gallo S, Pasquale S. Optical and colorimetric characterization on binary mixtures prepared with coloured and white historical pigments. Dyes Pigments 2018. https://doi.org/10.1016/j.dyepig.2018.04.068.

[41] Strauch D. New data and updates for IV-IV, III-V, II-VI and I-VII compounds, their mixed crystals and diluted magnetic semiconductors. Landolt-börnstein - gr III condens matter. Numer Data Funct Relationships Sci Technol 2011. https://doi. org/10.1007/978-3-642-14148-5_104.

[42] Upadhyay SK. Chemical kinetics and reaction dynamics. Dordrecht: Springer Netherlands; 2006. https://doi.org/10.1007/978-1-4020-4547-9.

[43] Prigogine I. Chemical kinetics and dynamics. Ann N Y Acad Sci 2003. https://doi. org/10.1111/j.1749-6632.2003.tb06091.x.

[44] Ross J, Garcia-Colin LS. Thermodynamics of chemical systems far from equilibrium. J Phys Chem 1989. https://doi.org/10.1021/j100342a075.

[45] Chaplin TD, Clark RJH, McKay A, Pugh S. Raman spectroscopic analysis of selected astronomical and cartographic folios from the early 13th century Islamic "Book of Curiosities of the Sciences and Marvels for the Eyes. J Raman Spectrosc 2006. https://doi.org/10.1002/jrs.1536.

[46] Muralha VSF, Miguel C, Melo MJ. Micro-Raman study of medieval cistercian 1213th century manuscripts: Santa Maria de Alcobaça, Portugal. J Raman Spectrosc 2012. https://doi.org/10.1002/jrs. 4065. 
[47] Burgio L, Clark RJH, Muralha VSF, Stanley T. Pigment analysis by Raman microscopy of the non-figurative illumination in 16th- to 18th-century Islamic manuscripts. J Raman Spectrosc 2008. https://doi.org/10.1002/jrs.2027.
[48] Klisińska-Kopacz A. Non-destructive characterization of 17th century painted silk banner by the combined use of Raman and XRF portable systems. J Raman Spectrosc 2015. https://doi.org/10.1002/jrs.4634.

[49] Standard I. International standard ISO/IEC. Quality; 2005. 